\title{
Dietary zinc inhibits the formation of colonic preneoplastic lesion induced by azoxymethane and dextran sodium sulfate in mice
}

\author{
Hyunji Park ${ }^{1}$, Dang Young Kim¹, Bong Su Kang ${ }^{1}$, Ja Seon Yoon ${ }^{1}$, Jae-Hwang Jeong ${ }^{2}$, \\ Sang Yoon Nam ${ }^{1}$, Young Won Yun ${ }^{1}$, Jong-Soo Kim ${ }^{1, *}$, Beom Jun Lee ${ }^{1, *}$ \\ ${ }^{1}$ College of Veterinary Medicine and Research Institute of Veterinary Medicine, Chungbuk National University, \\ Cheongju 361-763, Korea \\ ${ }^{2}$ Department of Biotechnology and Biomedicine, Chungbuk Province College, Okcheon 373-807, Korea \\ (Received: February 9, 2012; Revised: June 7, 2012; Accepted: June 8, 2012)
}

\begin{abstract}
Colorectal cancer (CRC) is one of the leading causes of cancer death in western countries or in the developed countries. Zinc intake has been associated with decreased risk of CRC. We investigated the effect of zinc on the formation of colonic aberrant crypt foci (ACF) induced by azoxymethane followed by dextran sodium sulfate in mice. Five-week old ICR mice were fed with the different zinc levels $(0.01$, $0.1,1 \mathrm{ppm})$ for 12 weeks. The numbers of ACF were measured in the colonic mucosa. The ACF number of $\mathrm{HZn}$ group was significantly low compared with $\mathrm{LZn}$ group or MZn group. Cytosolic superoxide dismutase activity was the highest in HZn group, while thiobarbituric acid reactive substance level for lipid peroxidation was the highest in LZn group. There was no difference in number of PCNA-positive proliferative cells among the groups. TUNEL-positive apoptotic cells were increased in HZn group compared with LZn group. The HZn group exhibited a decrease of $\beta$-catenin immunostaining areas compared with the $\mathrm{LZn}$ or MZn group. These findings indicate that dietary zinc might exert a protecting effect against colon carcinogenesis by inhibiting the development of ACF in the mice.
\end{abstract}

Keywords : aberrant crypt foci, colon carcinogenesis, mouse, zinc

\section{Introduction}

Colorectal cancer is one of the most common nonsmoking related cancers and leading causes of cancer death in western countries or in the developed countries $[16,34]$. In Korea, the incidence and mortality of colorectal cancer have gradually increased in the last decade, becoming one of the leading cause of cancer deaths [18]. Several animal models have been reported for inflammatory bowel disease (IBD) and IBD-related colorectal cancer. A mouse model for IBD induced with azoxymethane (AOM) and dextran sodium sulfate (DSS) has been used most widely [23]. The most commonly used colon carcinogens are 1, 2-dimethylhydrazine (DMH) and its metabolite AOM. The DMH or AOMinduced colon cancer shares many similarities to human sporadic colon cancer, including the response to some promotional and preventive agents [6]. The ultimate carcinogenic metabolite of DMH causes methylation of the DNA bases of various organs, including epithelial cells of colonic crypts [24]. Thus, this results in a loss of colonic cells by apoptosis, an increase in proliferation and mutation of colonic epithelial cells [5]. DSS induces colonic inflammation in rodents and promotes colon carcinogenesis, thereby being used for experimental animal colorectal cancer model [26]. AOM treatment during or after DSS administration do not generate a significant number of colonic neoplasm in mice, while DSS administration after AOM treatment could induce a number of colonic neoplasm [34].

By reason of relatively long developmental process of tumors, preneoplastic lesions can be used as biomarkers for assessing the risk of developing colon cancer or for identifying modulators of colon carcinogenesis in shortterm studies [4]. Aberrant crypt foci (ACF) were first reported on a method for directly visualizing altered crypts induced by carcinogens in the intact colon [3]. ACF are the first lesion in the development of colon

\footnotetext{
*Corresponding authors

Tel: +82-43-261-3357, Fax: +82-43-271-3246 (Beom Jun Lee)

E-mails: beomjun@cbu.ac.kr (Beom Jun Lee), jsvet@cbu.ac.kr (Jong-Soo Kim)
} 
cancer that can be identified microscopically on methylene blue-stained colon mucosa. ACF are characterized by enlarged and elevated dark crypts and increases pericryptal space [3].

$\beta$-catenin, acting as a structural protein and transcriptional activator-mediating Wnt signaling, is mostly localized at membranes of cell-to-cell border [27]. $\beta$-catenin mutations were frequently observed in AOM-induced colon cancer in rodents [14, 15, 32]. When $\beta$-catenin mutations occur, the protein localize to the cytoplasm or nucleus [17]. Crypts with increased $\beta$ catenin expression have been suggested as a more relevant biomarker of colon cancer than ACF [22, 35].

Zinc is vital for the function of all living systems. It is an essential trace element important for the stabilization and function of numerous metalloenzymes, especially copper-zinc superoxide dismutases [29]. Zinc plays an important role in the metabolism and interaction of malignant cells [10, 28]. Zinc has a stabilizing effect on membranes possibly by displacing bound transition metal ions and thereby preventing peroxidation of membrane lipids [2]. Moreover, it was founded that zinc had a protective effect against colonic preneoplastic development induced by DMH in rats [7].

Oxidative stress caused by reactive oxygen metabolites results in damage to cellular structure, thereby implicates in the initiation and promotion phases of carcinogenesis [8]. Malondialdehyde (MDA), product of lipid peroxidation, is one of the most frequently used indicators of lipid peroxidation. MDA is a mutagenic and genotoxic agent that may contribute to the development of human cancer because of its high cytotoxicity and inhibitory action on protective enzymes [11].

The aim of this study was to examine the role of zinc in the formation of colonic preneoplastic lesions induced by AOM/DSS in mice fed different levels of dietary zinc with normal (medium) iron status.

\section{Materials and Methods}

\section{Materials}

AOM was purchase from Sigma Chemical Company (USA). DSS (molecular weight 36,000 50,000) was purchased from MP Biomedicals (USA).

\section{Animals}

Male ICR mice aged 5 weeks were purchased from SLC Inc. (Japan), and housed in polycarbonate cages (5 mice/cage). Animals were fed on customized diet based on AIN-93G controlled purified rodent diet (Dyets, USA) and water was provided ad libitum, under controlled condition of temperature $\left(20 \pm 2^{\circ} \mathrm{C}\right)$, relative humidity $(50 \pm 20 \%)$ and light $(12 / 12 \mathrm{~h}$ light/dark cycle). The animal experiment was conducted in accordance with "Guide for care and use of laboratory animals" of Chungbuk National University, Korea. After one week of acclimatization, the animals were fed diets containing modified levels of iron and zinc. During the experimental period, weekly body weights and feed consumptions were recorded.

\section{Experimental design}

Twenty mice were assigned to each AOM/DSS treatment groups, while ten mice to vehicle control group (Fig. 1). For AOM/DSS treatment groups, animals

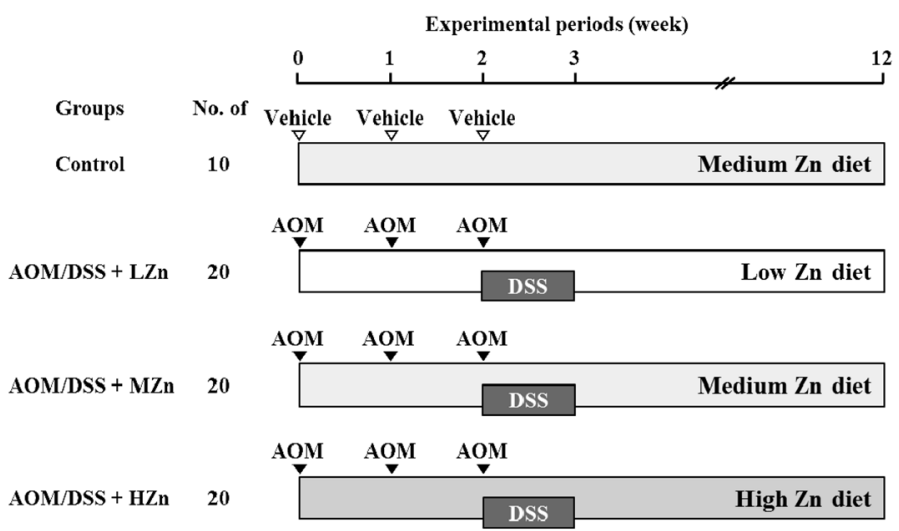

Fig. 1. Experimental design for colon carcinogenesis in mice fed different levels of dietary zinc. AOM: Azoxymethane $(10 \mathrm{mg} / \mathrm{kg}$ body weight in saline, I.P., weekly 3 times), DSS: Dextran sodium sulfate ( $2 \%$ in drinking water for a week). 
Table 1. Composition of the animal diets with medium level of iron and different levels of zinc

\begin{tabular}{lccc}
\hline \hline \multicolumn{1}{c}{ Groups } & $\mathrm{LZn}$ & $\mathrm{MZn}$ & $\mathrm{HZn}$ \\
\hline Ingredients & $\mathrm{g} / \mathrm{kg}$ & $\mathrm{g} / \mathrm{kg}$ & $\mathrm{g} / \mathrm{kg}$ \\
Casein & 200 & 200 & 200 \\
L-Cystine & 3 & 3 & 3 \\
Sucrose & 90.7 & 88.9 & 70.9 \\
Cornstarch & 397.486 & 397.486 & 397.486 \\
Dyetrose & 132 & 132 & 132 \\
Soybean Oil & 70 & 70 & 70 \\
t-Butylhydroquinone & 0.014 & 0.014 & 0.014 \\
Microcrystalline Cellulose & 50 & 50 & 50 \\
Mineral Mix \#215020 & 35.1 & 35.1 & 35.1 \\
Ferric Citrate P.M. 5 mg/g Fe & 9 & 9 & 9 \\
Zinc Carbonate P.M. 5 mg/g Zn & 0.2 & 2 & 20 \\
Vitamin Mix \# 310025 & 10 & 10 & 10 \\
Choline Bitartrate & 2.5 & 2.5 & 2.5 \\
Total gram & 1,000 & 1,000 & 1,000 \\
\hline
\end{tabular}

LZn: low zinc diet, MZn: medium zinc diet, HZn: high zinc diet.

were given a weekly intraperitoneal injection of AOM (10 mg/kg body weight in saline) for 3 weeks. After the last AOM injection, additional $2 \%$ DSS was given in the drinking water for 7 days. Additionally, the mice in three AOM/DSS treatment groups were fed a low-zinc diet (LZn; 1 ppm Zn), a medium-zinc diet (MZn; 10 ppm $\mathrm{Zn}$ ) and a high-zinc diet (HZn; 100 ppm Zn). In the control group, mice were injected with saline instead of AOM and no additional DSS was given. The mice in the control group were fed MZn (10 ppm Zn) which is recommended for regular rodent diet.

\section{Animal diets}

The AIN-93G purified rodent diet contained 20\% casein, $0.3 \%$ L-cystine, $39.7 \%$ cornstarch, $13.2 \%$ dyetrose, $7 \%$ soybean oil, $0.0014 \%$ t-butylhydroquinone, 5\% cellulose, $3.7 \%$ mineral mix, $1 \%$ vitamin mix, $0.25 \%$ choline bitartrate. $\mathrm{LZn}, \mathrm{MZn}$ and $\mathrm{HZn}$ contained zinc carbonate at the level of 1,10 and 100 ppm as zinc, respectively (Table 1 ).

\section{Sample collection and blood analysis}

Mice were sacrificed at 12 weeks after the experiment. After laparotomy, blood was collected by a syringe from the abdominal aorta and immediately transferred into tubes containing $\mathrm{K}_{3}$-EDTA and serum separator tubes (Vacutainer, USA). The liver and large intestine were harvested. One fifth of liver tissue was washed with saline, blot dried, weighed and then frozen in liquid nitrogen. A half of the large intestine from cecum to anus was longitudinally opened, flushed with saline, and fixed in $10 \%$ neutral buffered formalin. The other half was washed with saline, blot dried and then frozen in liquid nitrogen. Blood samples in EDTA tubes were used for analysis of complete blood cell count with Abbott CellDyn-3500 (Abbott Laboratories, USA).

\section{Analysis of hepatic iron}

For the determination of total iron concentrations in the liver, frozen liver tissues were digested and ashed at $200^{\circ} \mathrm{C}$ for $4 \mathrm{~h}$ using concentrated nitric acid and hydrogen peroxide, and analysed by inductively coupled plasma spectrophotometer (ICP-AES; JY 38 Plus, France).

\section{Hepatic superoxide dismutase activity assay}

Superoxide dismutase (SOD) activity was measured using a commercial assay kit (Cayman Chemical, USA) according to manufacturer's instructions. This kit utilizes a tetrazolium salt for the detection of superoxide radicals generated by xanthine oxidase and hypoxanthine. One unit of SOD was defined as the amount of enzyme needed to produce $50 \%$ dismutation of superoxide radicals. To separate SOD, liver homogenate was centrifuged at $1,500 \times \mathrm{g}$ for $10 \mathrm{~min}$ and the supernatant was centrifuged at $10,000 \times \mathrm{g}$ for $15 \mathrm{~min}$ at $4^{\circ} \mathrm{C}$. The resulting 10,000 $\times \mathrm{g}$ supernatant, containing cytosolic SOD, was collected and analyzed for SOD activity.

\section{Determination of lipid peroxidation in liver}

The level of MDA, an end product of lipid peroxidation, was determined in the liver. The amounts of MDA contained in the tissue homogenate were measured using a thiobarbituric acid reactive substance (TBARS) assay kit (Cayman Chemical, USA) according to manufacturer's instructions. In brief, MDA-TBA adduct was formed by the reaction of MDA and TBA under high temperature $\left(90 \sim 100^{\circ} \mathrm{C}\right)$ and acidic condition. The MDA-TBA adduct appeared as pink chromogen, and was measured at $532 \mathrm{~nm}$.

\section{Analysis of aberrant crypt foci}

The colon was stained with $0.5 \%$ methylene blue solution for $30 \mathrm{sec}$ in order to identify ACF. The 
numbers of ACF in each focus were counted under a microscope. ACF were identified with the following morphological characteristics: 1) the enlarged and elevated crypts than normal mucosa, and 2) increased pericryptal space and irregular lumens [19].

\section{Histopathological examination}

The colon tissues fixed in $10 \%$ neutral buffered formalin were paraffin-embedded, cut to multiple $4-\mu \mathrm{m}$ sections, and stained with hematoxylin and eosin for histopathological examination.

\section{Immunohistochemistry}

Immunohistochemistry for proliferating cell nuclear antigen (PCNA) and $\beta$-catenin was performed on 4-m formalin-fixed, paraffin-embedded distal colon sections. The sections were subjected to deparaffinization and hydration prior to quenching of endogenous peroxidase activity ( $3 \% \mathrm{H}_{2} \mathrm{O}_{2}$ in methanol for $\left.15 \mathrm{~min}\right)$. The sections were incubated for $60 \mathrm{~min}$ with the primary anti-PCNA mouse monoclonal antibody (Santa Cruz Biotechnology, USA) and anti- $\beta$-catenin rabbit polyclonal antibody (Santa Cruz Biotechnology, USA). Slides were processed with the $\mathrm{ABC}$ reagent from Vectastain Elite kit (Vector Laboratories, USA) and developed with the 3, 3'diaminobenzidine, tetrahydrochloride. The sections were counter-stained with mayer hematoxylin. Twenty fields, randomly selected from each slide, were analyzed at 100x magnification. The numbers of nuclei with positive reactivity for PCNA immunohistochemistry were counted in a total of $3 \times 100$ cells in 3 different areas of the colonic cancer [33]. The expression of $\beta$-catenin was graded by intensity of nuclear staining accompanied by loss of membranous staining as negative (localization limited to membrane), focal positive (positive cells clustered in focal area) and diffuse positive (positive cells distributed diffusely), described by Kobayashi et al. [17]. Cytoplasmic immunoreactivity was not considered in this study because the expression was variable and not clearly related to the shift from membranous to nuclear staining.

\section{TUNEL assay}

Levels of apoptosis in distal colon tissue were determined using the TdT-mediated dUTP nick-end labeling (TUNEL) method. The $4-\mu \mathrm{m}$ formalin-fixed, paraffin-embedded tissue sections from the distal colon were processed according to manufacturer's instructions

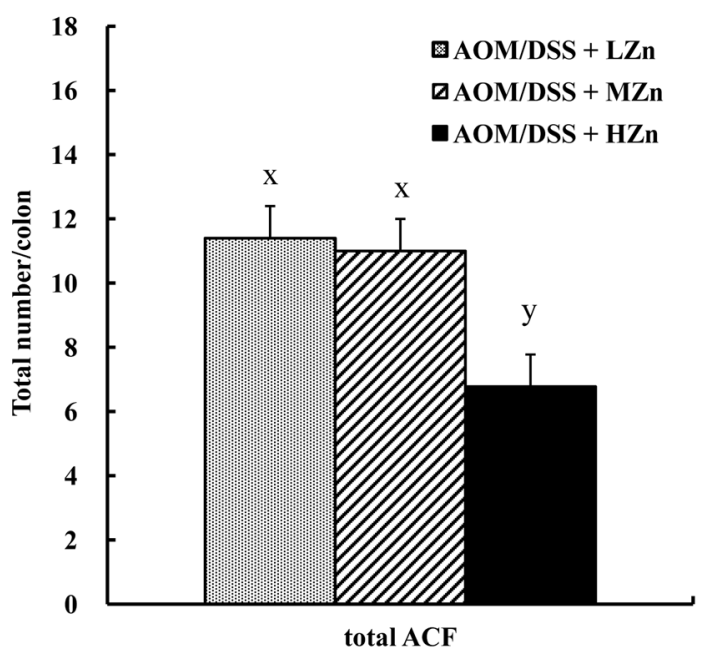

Fig. 2. Effect of zinc on colonic aberrant crypt foci formation in mice. ACF: aberrant crypt foci, AOM: azoxymethane, DSS: dextran sodium sulfate, LZn: low-zinc diet, MZn: medium-zinc diet, HZn: high-zinc diet. Each bar represents the mean $\pm \mathrm{SD}$. Means with different letter are significantly different $\left({ }^{\mathbf{x y}} p<0.01\right)$.

for the ApopTag peroxidase in situ apoptosis detection kit (Vector Laboratories, USA). The numbers of nuclei with positive reactivity for TUNEL assay were counted in a total of $3 \times 100$ cells in 3 different areas of the colonic mucosa [33].

\section{Statistical analysis}

Data of ACF, PCNA and TUNEL assay were analyzed by Dunn's multiple comparison test after Kruskal-Wallis' nonparametric ANOVA. Other parametric data were analyzed by one-way analysis of variance and significant differences among treatment groups were evaluated by Tukey-Kramer test. For all comparisons, $p$ $<0.05$ was considered statistically significant.

\section{Results}

\section{Total number of aberrant crypt foci}

The animals in vehicle control group showed no evidence of ACF formation in the colon with high iron diet. The number of ACF in HZn group $(6.78 \pm 3.61)$ was significantly low compared with LZn group (11.40 $\pm 2.92)$ or MZn group $(11.00 \pm 2.30)(p<0.01)$ (Fig. 2).

\section{Superoxide dismutase in the liver}

The levels of SOD in LZn group $(9.09 \pm 1.35)$ and 


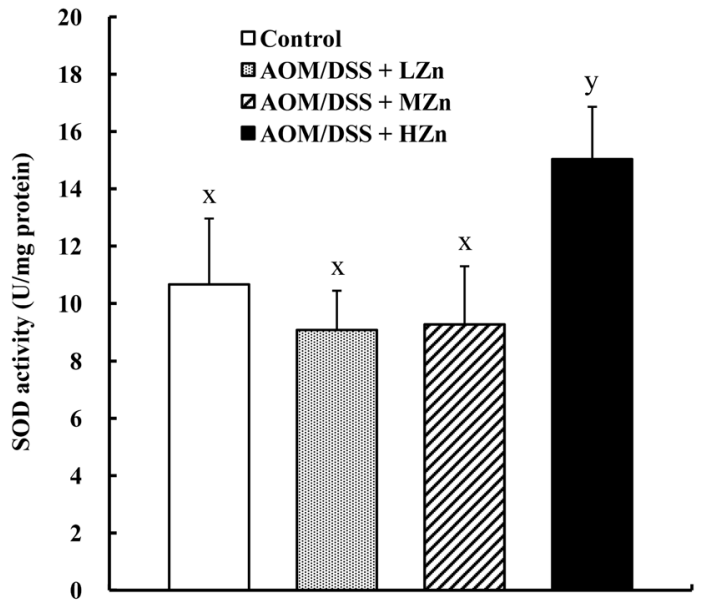

Fig. 3. Effect of zinc on superoxide dismutase in the liver of mice subjected to AOM/DSS treatment. SOD: superoxide dismutase, AOM: azoxymethane, DSS: dextran sodium sulfate, LZn: low-zinc diet, MZn: medium-zinc diet, HZn: high-zinc diet. Data represented as mean $\pm \mathrm{SD}$. Means with different letter are significantly different $\left({ }^{\mathbf{x y}} p<0.01\right)$.

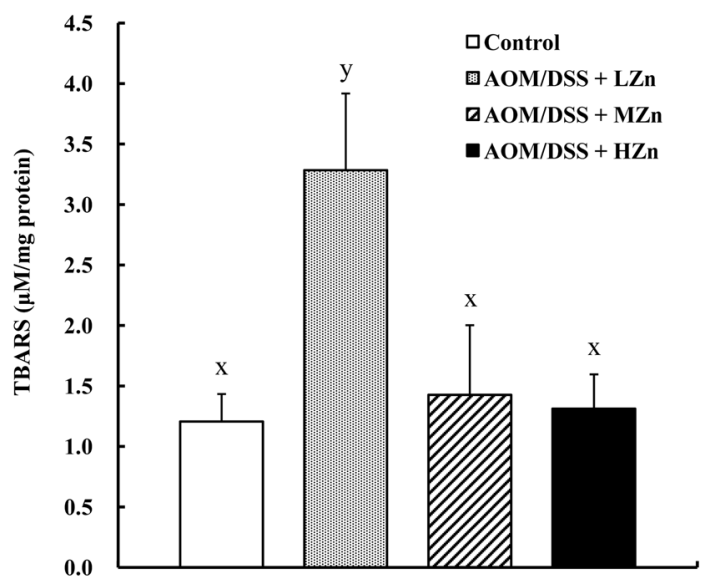

Fig. 4. Effect of zinc on lipid peroxidation in the liver of mice subjected to AOM/DSS treatment. TBARS: thiobarbituric acid reactive substance, AOM: azoxymethane, DSS: dextran sodium sulfate, $\mathrm{LZn}$ : low-zinc diet, MZn: mediumzinc diet, HZn: high-zinc diet. Data represent the mean \pm SD. Means with different letter are significantly different $\left({ }^{\mathbf{x y}} p<0.01\right)$.

MZn group $(9.28 \pm 2.02)$ were not significantly different from control group $(10.66 \pm 2.30)$. HZn group (18.12 \pm $1.53)$ showed significantly higher SOD level compared with LZn group $(p<0.01)$ (Fig. 3).
Table 2. Effect of zinc on cell proliferative index and apoptotic index of mice

\begin{tabular}{lcc}
\hline \hline \multicolumn{1}{c}{ Groups } & $\begin{array}{c}\text { Proliferative } \\
\text { index (\%) }\end{array}$ & $\begin{array}{c}\text { Apoptotic } \\
\text { index (\%) }\end{array}$ \\
\hline Control & $39.13 \pm 5.68^{\mathrm{x}}$ & $0.7 \pm 0.82^{\mathrm{a}}$ \\
$\mathrm{AOM} / \mathrm{DSS}+\mathrm{LZn}$ & $49.27 \pm 7.55^{\mathrm{y}}$ & $1.5 \pm 1.08^{\mathrm{ab}}$ \\
$\mathrm{AOM} / \mathrm{DSS}+\mathrm{MZn}$ & $47.67 \pm 6.81^{\mathrm{y}}$ & $3.3 \pm 1.70^{\mathrm{b}}$ \\
$\mathrm{AOM} / \mathrm{DSS}+\mathrm{HZn}$ & $46.80 \pm 4.66^{\mathrm{y}}$ & $7.6 \pm 2.84^{\mathrm{c}}$ \\
\hline
\end{tabular}

AOM: azoxymethane, DSS: dextran sodium sulfate, LZn: low zinc diet, MZn: medium zinc diet, HZn: high zinc diet. Data represented as mean \pm SD. Means in each column with different superscripts are significantly different $\left({ }^{\mathrm{ab},} \mathrm{bc},{ }^{\mathrm{xy}} p<\right.$ $\left.0.05,{ }^{\mathrm{ac}} p<0.01\right)$.

\section{Lipid peroxidation level in the liver}

The MDA levels in the liver were $1.21 \pm 0.23 \mu \mathrm{M} / \mathrm{mg}$ protein for the control group, $3.28 \pm 0.63 \mu \mathrm{M} / \mathrm{mg}$ protein for the $\mathrm{LZn}$ group, $1.43 \pm 0.58 \mu \mathrm{M} / \mathrm{mg}$ protein for the $\mathrm{MZn}$ group and $1.31 \pm 0.28 \mu \mathrm{M} / \mathrm{mg}$ protein for the $\mathrm{HZn}$ group, respectively. The $\mathrm{LZn}$ group showed a significantly increased level of MDA compared with the other groups $(p<0.01)$ (Fig. 4)

\section{Histopathology}

Vehicle control group displayed normal colonic architecture with no sign of apparent abnormality. In all of AOM/DSS-treated groups, thickened epithelium and both dysplasia and/or hyperplasia were observed (Fig. 5).

Changes in cell proliferation and apoptosis in colon Cell proliferation was evaluated by quantification of PCNA positive cells (Fig. 6). There was no significant difference among the AOM/DSS treated experimental groups (Table 2). Apoptotic bodies were visualized by TUNEL method (Fig. 7). The colon epithelium of the mice in $\mathrm{HZn}$ group showed significantly higher count of apoptotic bodies compared with MZn group and LZn group treated with AOM/DSS $(p<0.05, p<0.01)$ (Table 2).

\section{Immunohistochemistry of $\boldsymbol{\beta}$-catenin}

The colonic mucosa of control group did not show the nuclear localization of $\beta$-catenin (Fig. 8A). Strong cytoplasmic and nuclear $\beta$-catenin immunoreactivity was observed on the epithelial cells of LZn and MZn groups (Figs. 8B and C). On the other hand, the nuclear $\beta$ catenin immunoreactivity in HZn group was weak (Fig. 

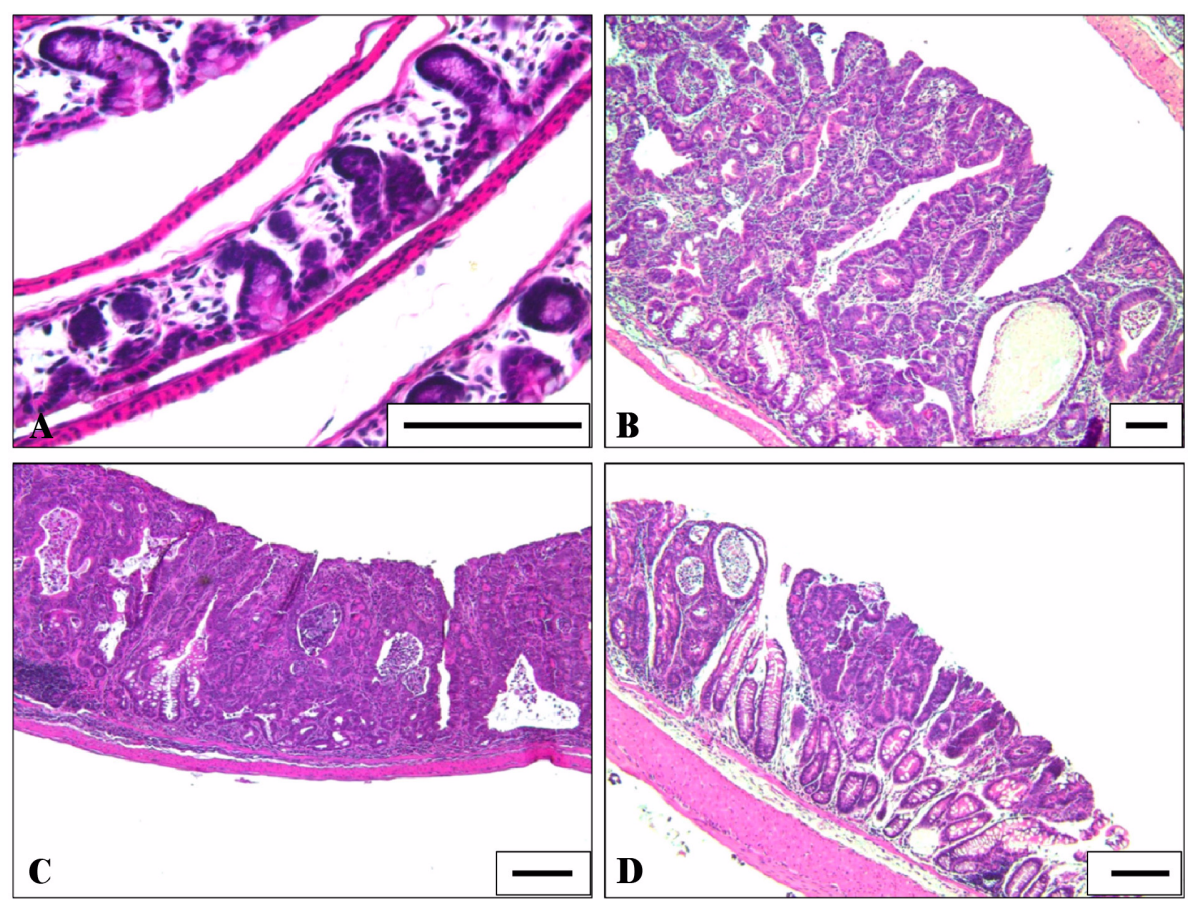

Fig. 5. Histopathology of colonic epithelium of mice fed different levels of dietary zinc. (A) Control group, (B) low-zinc diet group, (C) medium-zinc diet group, (D) high-zinc diet group. Scale bars: $100 \mu \mathrm{m}$.
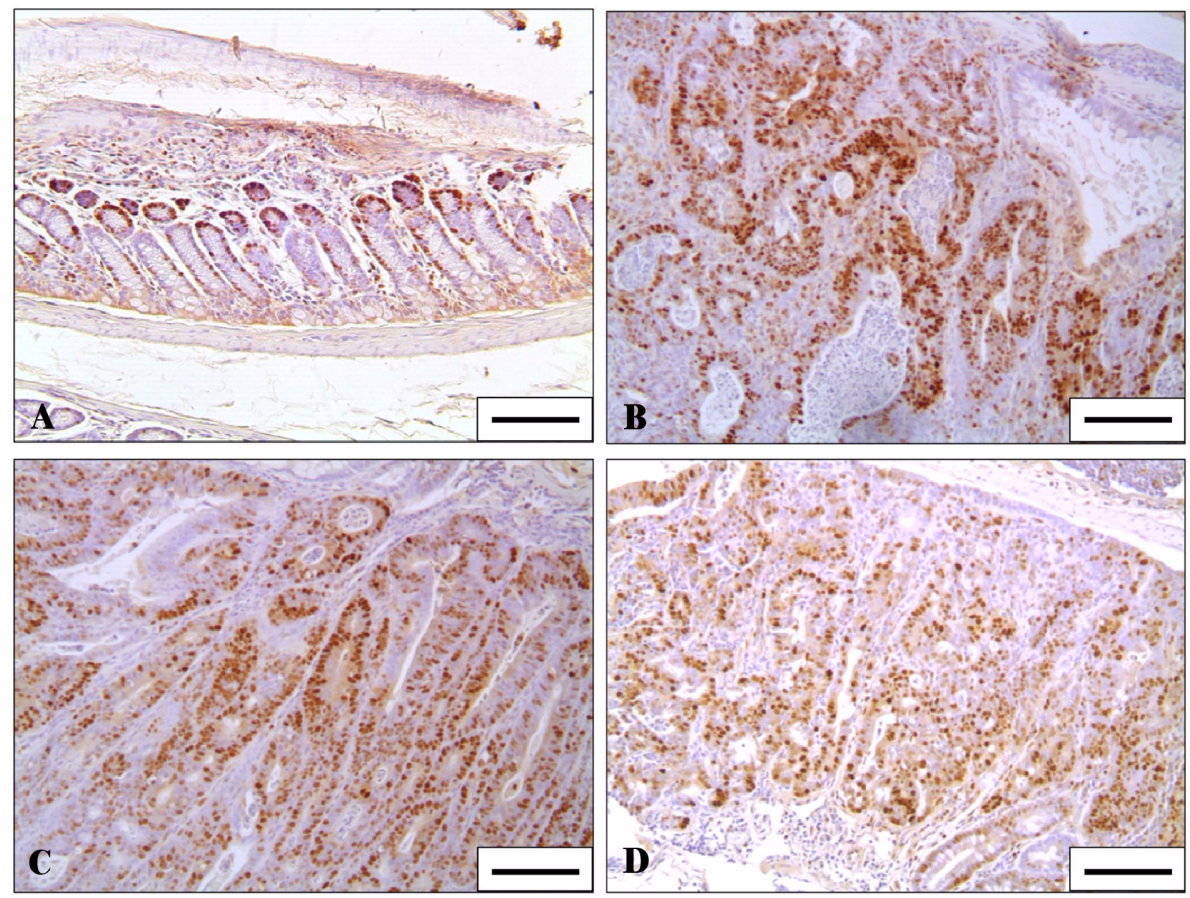

Fig. 6. Immunohistochemistry of proliferating cell nuclear antigen in the colon of mice fed different levels of dietary zinc. (A) Control group, (B) low-zinc diet group, (C) medium-zinc diet group, (D) high-zinc diet group. Scale bars: $100 \mu \mathrm{m}$. 

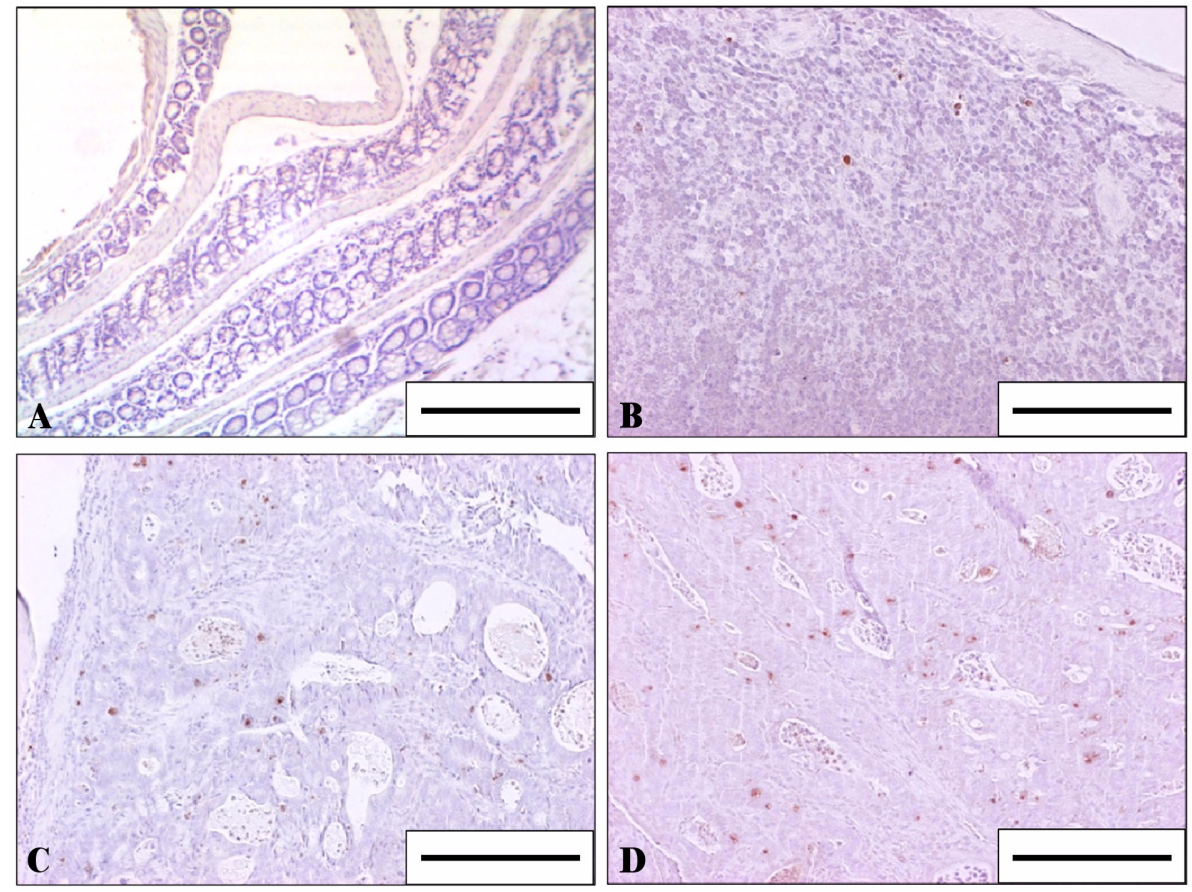

Fig. 7. TUNEL assay for apoptotic nuclei in distal colon of mice fed different levels of dietary zinc. (A) Control group, (B) low-zinc diet group, (C) medium-zinc diet group, (D) high-zinc diet group. Scale bars: $100 \mu \mathrm{m}$.
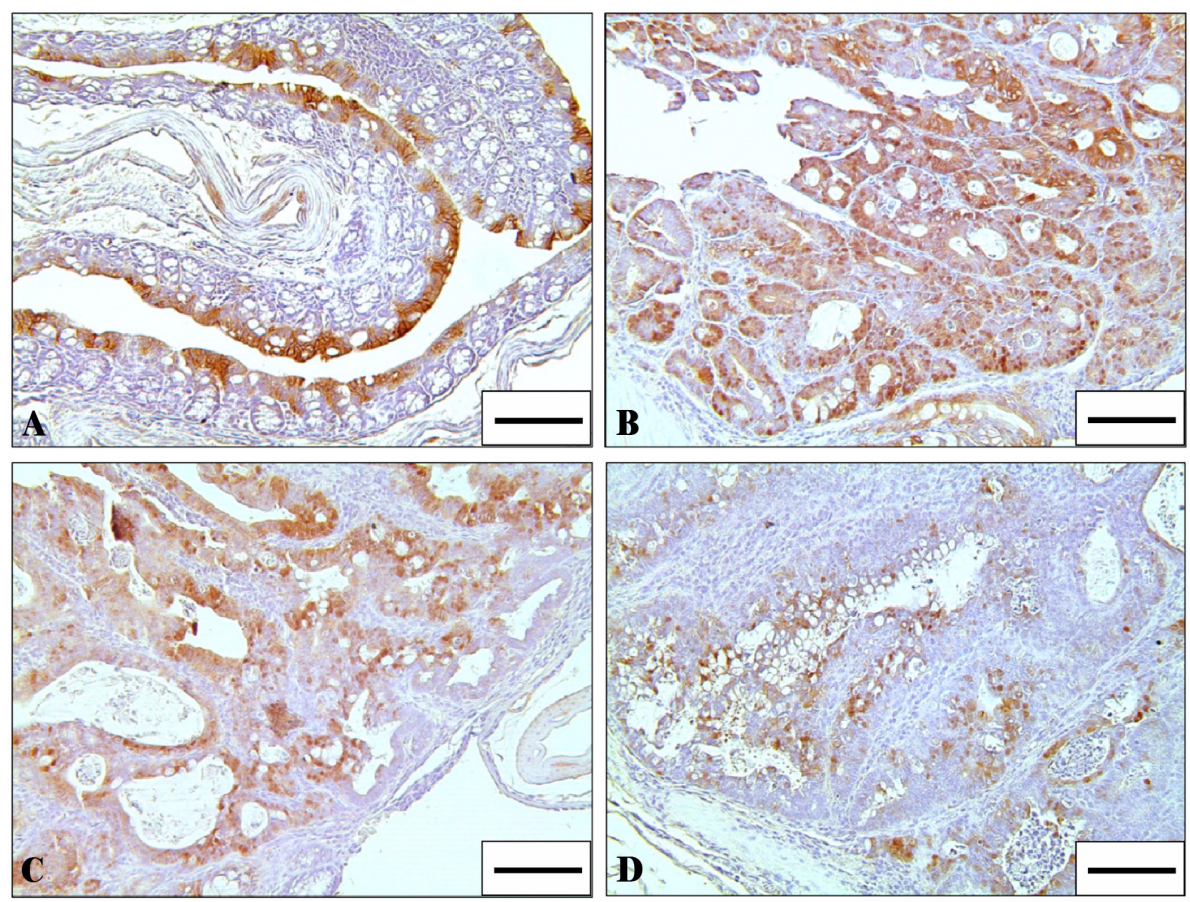

Fig. 8. Immunohistochemistry of $\beta$-catenin on distal colon of mice fed different levels of dietary zinc. (A) Control group, (B) low-zinc diet group, (C) medium-zinc diet group, (D) high-zinc diet group. Scale bars: $100 \mu \mathrm{m}$. 
8D). No significant differences were found in the number of cells with nuclear $\beta$-catenin expression among the AOM/DSS treated groups, and in the distribution of $\beta$ catenin expression patterns (data not shown).

\section{Discussion}

Colon is the most common site for malignancies of gastrointestinal tract and colon cancer does not appear to be a result of aging, but is intrinsically associated with dietary pattern. Red and processed meat consumption promotes the risk of colorectal cancer, and this promotion is found to correlate closely with dietary iron [9]. Dani et al. [7] reported that zinc inhibited the formation of ACF suggesting the potential of zinc in suppressing the progression of preneoplasia to malignant neoplasia and the suppressing effect of zinc could be explained by its putative antioxidant activity.

We examined the effects of zinc on the formation of colonic preneoplastic lesions induced by AOM/DSS in mice. ACF are putative preneoplastic lesions that have been detected in human colon cancer and experimental animals treated with chemical carcinogen. ACF can be identified microscopically on the surface of the whole mount colon mucosa after methylene blue staining. They are distinguished from normal crypts by their larger size, darker staining and increased pericryptal space [3].

In this study, the numbers of ACF were significantly lower in HZn group compared with LZn group and MZn group. In addition, the number of large ACF, which possess greater tumorigenic potential [20], was lower in HZn group compared with LZn group and MZn group. These results suggest that dietary supplement of zinc induces an inhibition of ACF formation in mice.

Colon carcinogenesis is a pathological consequence of persistent oxidative stress, leading to DNA damage and multiple genetic changes that may be caused by overproduction of reactive oxygen species in cancerrelated genes [1]. The enzyme SOD promotes the conversion of superoxide free-radical anions into hydrogen peroxide. SOD has been shown to have a protective effect against lipid peroxidation [31]. The levels of SOD in $\mathrm{LZn}$ and MZn group were not significantly different from control group. However, the level of SOD in HZn group was significantly increased compared with $\mathrm{LZn}$ group. These findings suggest that high zinc diet plays an effective role in promotion of SOD activity.

Oxidative stress can result in cellular injury due to lipid peroxidation, DNA damage and mutagenesis, and it has been associated with various stage of tumor formation process $[13,30]$. TBA reacts with MDA or MDA-like derives formed during the oxidative decomposition of polyunsaturated fats to form a colored product [25]. Lipid peroxidation in the liver of MZn group and $\mathrm{HZn}$ group were significantly decreased compared with LZn group. These findings suggest that dietary zinc may play a protective role in colonic carcinogenesis through the inhibition of lipid peroxidation.

PCNA is a non-histone nuclear protein and associated with DNA synthesis phase of the cell cycle, and frequently used for the marker of cell proliferation. In this study, dietary zinc did not induce any changes in cell proliferation induced by AOM/DSS in colonic epithelial cells. TUNEL of normal rodent large intestine stains only the uppermost nuclei at the edge of the crypt facing the lumen, while the rest of the crypt remains unstained [12]. TUNEL assay was performed in order to confirm the association between dietary zinc levels and apoptosis of tumorigenic cells induced by AOM/ DSS in iron-overloaded status. The epithelium of colon in HZn group showed a markedly higher count of apoptotic bodies compared with other AOM/DSS-treated groups (LZn and MZn), indicating that high dietary zinc might induce upregulation of programmed cell death of tumorigenic cells.

$\beta$-catenin is an important factor in Wnt signaling and thereby regulating transcription of genes related to proliferation and development of cells [21]. In colon carcinogenesis, $\beta$-catenin accumulates in nucleus and/or cytosol. Alteration of $\beta$-catenin may play an important role in causing early dysplastic change [32]. $\beta$-catenin expression was mostly localized at membranes of colonic mucosa in control group. LZn and MZn groups showed an increased nuclear $\beta$-catenin expression compared with HZn group. Especially in LZn group, strong $\beta$-catenin expression was seen in the nucleus and cytoplasm. However, more detailed quantitative analysis is required to conclude the relationship between dietary zinc level and $\beta$-catenin mutation.

In conclusion, high dietary zinc reduced the formation of colonic aberrant crypt, ACF, and multiplicity of ACF, promoted hepatic SOD activity, reduced lipid peroxidation, and increased apoptosis of tumorigenic cells induced by AOM/DSS. These findings suggest that zinc may play a possible protective role in colon carcinogenesis in mice. 


\section{Acknowledgments}

This work was supported by Priority Research Centers Program through the National Research Foundation of Korea (NRF) funded by the Ministry of Education, Science and Technology (2011-0031403) and National Research Foundation Grant funded by the Ministry of Education, Science and Technology (NRF-2008-313E00628).

\section{References}

1. Bartsch H, Nair J. Potential role of lipid peroxidation derived DNA damage in human colon carcinogenesis: studies on exocyclic base adducts as stable oxidative stress markers. Cancer Detect Prev 2002, 26, 308-312.

2. Bettger WJ, Reeves PG, Savage JE, O'Dell BL. Interaction of zinc and vitamin $\mathrm{E}$ in the chick. Proc Soc Exp Biol Med 1980, 163, 432-436.

3. Bird RP. Observation and quantification of aberrant crypts in the murine colon treated with a colon carcinogen: preliminary findings. Cancer Lett 1987, 37, 147-151.

4. Bird RP. Aberrant crypt foci system to study cancer preventive agents in the colon. In: Hanausek M, Walaszek Z (eds.). Tumor Marker Protocols. pp. 465474. Humana Press, New Jersey, 1998.

5. Chang WW. Histogenesis of colon cancer in experimental animals. Scand J Gastroenterol Suppl 1984, 104, 27-43.

6. Corpet DE, Pierre F. How good are rodent models of carcinogenesis in predicting efficacy in humans? A systematic review and meta-analysis of colon chemoprevention in rats, mice and men. Eur J Cancer 2005, 41, 1911-1922.

7. Dani V, Goel A, Vaiphei K, Dhawan DK. Chemopreventive potential of zinc in experimentally induced colon carcinogenesis. Toxicol Lett 2007, 171, 10-18.

8. Davis CD, Feng Y. Dietary copper, manganese and iron affect the formation of aberrant crypts in colon of rats administered 3,2'-dimethyl-4-aminobiphenyl. J Nutr 1999, 129, 1060-1067.

9. Doll R, Peto R. The causes of cancer: quantitative estimates of avoidable risks of cancer in the United States today. J Natl Cancer Inst 1981, 66, 1191-1308.

10. Evans $P$, Halliwell B. Micronutrients: oxidant/antioxidant status. Br J Nutr 2001, 85 (Suppl 2), S67-74.
11. Feron VJ, Til HP, de Vrijer F, Woutersen RA, Cassee FR, van Bladeren PJ. Aldehydes: occurrence, carcinogenic potential, mechanism of action and risk assessment. Mutat Res 1991, 259, 363-385.

12. Gavrieli Y, Sherman Y, Ben-Sasson SA. Identification of programmed cell death in situ via specific labeling of nuclear DNA fragmentation. J Cell Biol 1992, 119, 493-501.

13. Halliwell B, Gutteridge JMC. Free Radicals in Biology and Medicine. 2nd ed. pp. 86-179. Clarendon Press, Oxford, 1989.

14. Hata K, Yamada Y, Kuno T, Hirose Y, Hara A, Qiang SH, Mori H. Tumor formation is correlated with expression of $\beta$-catenin-accumulated crypts in azoxymethane-induced colon carcinogenesis in mice. Cancer Sci 2004, 95, 316-320.

15. Hirose Y, Kuno T, Yamada Y, Sakata K, Katayama M, Yoshida K, Qiao Z, Hata K, Yoshimi N, Mori H. Azoxymethane-induced beta-catenin-accumulated crypts in colonic mucosa of rodents as an intermediate biomarker for colon carcinogenesis. Carcinogenesis 2003, 24, 107-111.

16. Jemal A, Bray F, Center MM, Ferlay J, Ward E, Forman D. Global cancer statistics. CA Cancer J Clin 2011, 61, 69-90.

17. Kobayashi M, Honma T, Matsuda Y, Suzuki Y, Narisawa R, Ajioka Y, Asakura H. Nuclear translocation of beta-catenin in colorectal cancer. $\mathrm{Br} \mathbf{J}$ Cancer 2000, 82, 1689-1693.

18. Korea National Statistical Office. Death and cause of death statistics 2010. Korea National Statistical Office, Daejeon, 2011.

19. McLellan EA, Bird RP. Aberrant crypts: potential preneoplastic lesions in the murine colon. Cancer Res 1988, 48, 6187-6192.

20. McLellan EA, Medline A, Bird RP. Dose response and proliferative characteristics of aberrant crypt foci: putative preneoplastic lesions in rat colon. Carcinogenesis 1991, 12, 2093-2098.

21. Miller JR, Moon RT. Signal transduction through $\beta$ catenin and specification of cell fate during embryogenesis. Genes Dev 1996, 10, 2527-2539.

22. Mori H, Yamada Y, Kuno T, Hirose Y. Aberrant crypt foci and $\beta$-catenin accumulated crypts; significance and roles for colorectal carcinogenesis. Mutat Res 2004, 566, 191-208.

23. Okayasu I, Hatakeyama S, Yamada M, Ohkusa T, 
Inagaki Y, Nakaya R. A novel method in the induction of reliable experimental acute and chronic ulcerative colitis in mice. Gastroenterology 1990, 98, 694-702.

24. Perše M, Cerar A. Morphological and molecular alterations in 1,2 dimethylhydrazine and azoxymethane induced colon carcinogenesis in rats. $\mathrm{J}$ Biomed Biotechnol 2011, 2011, 473964.

25. Rael LT, Thomas GW, Craun ML, Curtis CG, BarOr R, Bar-Or D. Lipid peroxidation and the thiobarbituric acid assay: standardization of the assay when using saturated and unsaturated fatty acids. J Biochem Mol Biol 2004, 37, 749-752.

26. Rosenberg DW, Giardina C, Tanaka T. Mouse models for the study of colon carcinogenesis. Carcinogenesis 2009, 30, 183-196.

27. Ross JS. Experimental large intestinal adenocarcinoma induced by hydrazine and human colorectal cancer: a comparative study. In: Malt RA, Williamson RCN (eds.). Colonic Carcinogenesis. pp. 187-207. MTP Press Limited, Lancaster, 1982.

28. Schrauzer GN. Trace elements, nutrition and cancer: perspectives of prevention. Adv Exp Med Biol 1977, 91, 323-344.

29. Sky-Peck HH. Trace metals and neoplasia. Clin Physiol Biochem 1986, 4, 99-111.

30. Stohs SJ, Bagchi D. Oxidative mechanisms in the toxicity of metal ions. Free Radic Biol Med 1995, 18, 321-336.

31. Sun JY, Jing MY, Weng XY, Fu LJ, Xu ZR, Zi NT, Wang JF. Effects of dietary zinc levels on the activities of enzymes, weights of organs, and the concentrations of zinc and copper in growing rats. Biol Trace Elem Res 2005, 107, 153-165.

32. Takahashi M, Fukuda K, Sugimura T, Wakabayashi K. $\beta$-catenin is frequently mutated and demonstrates altered cellular location in azoxymethane-induced rat colon tumors. Cancer Res 1998, 58, 42-46.

33. Tanaka T, de Azevedo MBM, Durán N, Alderete JB, Epifano F, Genovese S, Tanaka M, Curini $M$. Colorectal cancer chemoprevention by $2 \beta$-cyclodextrin inclusion compounds of auraptene and 4'-geranyloxyferulic acid. Int J Cancer 2010, 126, 830-840.

34. Tanaka T, Kohno H, Suzuki R, Yamada Y, Sugie S, Mori H. A novel inflammation-related mouse colon carcinogenesis model induced by azoxymethane and dextran sodium sulfate. Cancer Sci 2003, 94, 965-973.

35. Yamada Y, Yoshimi N, Hirose Y, Kawabata K, Matsunaga K, Shimizu M, Hara A, Mori $\mathbf{H}$. Frequent $\beta$-catenin gene mutations and accumulations of the protein in the putative preneoplastic lesions lacking macroscopic aberrant crypt foci appearance, in rat colon carcinogenesis. Cancer Res 2000, 60, 33233327. 